ISSN 1822-427X/eISSN 1822-4288

2021 Volume 16 Issue 2: 127-150 https://doi.org/10.7250/bjrbe.2021-16.527
THE BALTIC JOURNAL

\title{
DESIGN OPTIMISATION ANALYSIS \\ OF ISOLATING WALL FOR SEPARATED \\ WIDENING EMBANKMENT ON SOFT GROUND
}

\author{
XIN JIANG*, YONGGUO FU, LINYU LI, \\ HANYAN GU, YANJUN QIU \\ School of Civil Engineering, \\ MOE Key Laboratory of High-Speed Railway Engineering, \\ Highway Engineering Key Laboratory of Sichuan Province, \\ Southwest Jiaotong University, Chengdu, China
}

Received 4 September 2020; accepted 21 December 2020

\begin{abstract}
In this paper, the typical cases of subgrade separated widening project in China are summarised. The research progress of subgrade separated widening and isolating wall applications are reviewed in highway reconstruction and extension. A numerical model is established based on the PLAXIS finite element software, considering both material nonlinearity and geometric nonlinearity. The effect mechanism of the isolating wall is discussed on the settlement control of the new and existing embankment on soft ground. The effect rule of the core design parameters of the isolating wall is revealed on the settlement disturbance of the existing embankment, such as location, depth, thickness and elastic modulus, and the weight rank of the influence is analysed. The results indicate that the isolating wall effectively reduces the lateral displacement and vertical settlement of the existing embankment, and there is an optimal design location for the isolating wall. In addition, with the increase
\end{abstract}

\footnotetext{
* Corresponding author. E-mail: xjiang01@163.com

Xin JIANG (ORCID ID 0000-0002-3044-5495)

Yongguo FU (ORCID ID 0000-0003-1416-5992)

Linyu LI (ORCID ID 0000-0002-8420-7281)

Hanyan GU (ORCID ID 0000-0003-2881-6282)

Yanjun QIU (ORCID ID 0000-0002-2250-5363) 
of design parameters of the isolating wall, including depth, thickness and elastic modulus, the overall settlement of the existing embankment tends to be uniform, and there are optimal values. Furthermore, the depth of isolating wall is given priority, compared to location, thickness and elastic modulus during the isolating wall design process. The research results lay a theoretical foundation for the design optimisation of the isolating wall in the separated widening project of soft ground.

Keywords: double nonlinearity, embankment separated widening, influence weight rank, isolating wall, soft ground.

\section{Introduction}

In recent years, with the rapid growth of vehicle ownership, countries worldwide are building more new roads to increase the density of the road network while setting off the climax of road widening better to meet the increasingly evident demand of traffic on roads. In China, the Guangzhou-Foshan Expressway opened the prelude to the highway widening project in 1997. Since then, more highways have been widened successively, such as Shanghai-Hangzhou-Ningbo Expressway (Jia et al., 2004), Shanghai-Nanjing Expressway (Lu et al., 2020), ShenyangDalian Expressway (Nie et al., 2005). Other countries of Europe and North American are also actively carrying out the roadbed widening project, for example, widening and upgrade of two interstate highways in Indiana, USA (Ludlow et al., 1992); the A16 between Antwerp and Rotterdam (Vos et al., 1994); the major highway, A2, between Utrecht and Amsterdam, in the Netherlands (Van Meurs et al., 1999); and the N247 in the northern Netherlands (Habib et al., 2002). The White Paper "Roads for Prosperity" of the UK Government pointed out that "about $60 \%$ of the motorway network in England, as well as some truck roads, will need to be widened by the provision of additional lanes" (Han et al., 2007).

It is noted that some developed countries of Europe and North American have considered the need for future road upgrading and capacity expansion in the initial stage of road network planning. The existing roads are widened by widening the inner side, widening by using a wide central separate belt (Liu, 2001), such as Highway 15 in the United States and Highway 401 in Canada (Yuan \& Zheng, 2017). However, highway widening in China and other countries adopt mostly direct splicing and widening on both sides or one side of the original road to form an integral embankment in plain and hilly areas. In contrast, the embankment reconstruction and extension form should be separated widening, for the mountainous area or the local complex road segment with many engineering constraints such as terrain, geological 
conditions and existing structures, as well as the long road segment with obvious transit traffic characteristics and without entrance and exit in the middle. The details are shown in Figure 1.

Compared to the splicing widening, although to a certain extent, the separated widening of embankment avoids the potential differential settlement risk between the new and existing embankment, to ensure the normal in-service of the existing embankment during the widening and reconstruction period, the settlement impact of the new embankment on the existing embankment and the post-construction settlement of the new embankment still need to be attached great importance. As one of the effective measures to reduce the settlement influence of separated widening new embankment on the original embankment, the isolating wall is now of increasing concern. The isolating wall is formed by high-pressure jet grouting of cement slurry material to isolate the adverse effects on the foundation seepage, deformation, and stability. It has the outstanding advantages of mature construction technology and low construction cost ( $\mathrm{Su}, \& \mathrm{Xu}, 2000)$. Moreover, it has shown good feasibility in the field test of the separated widening project of Xicheng and Huning Expressway (He et al., 1998a, 1998b; Su, \& Xu, 2000; Xu et al., 1998), but its deep theoretical research lags far behind the engineering practice. Therefore, this paper sorts out typical cases of separated widening of embankment in China, reviews the research progress of separated widening of embankment and application of isolating wall in highway reconstruction and extension, studies the effect rule of separated widening isolating wall on differential settlement of existing embankment, and analyses the effect weight of location, depth, thickness and elastic modulus of isolating wall on settlement disturbance of existing embankment.
Xin Jiang,

Yongguo Fu,

Linyu $L i$,

Hanyan Gu,

Yanjun Qiu

Design Optimisation Analysis of Isolating Wall for Separated

Widening

Embankment on Soft Ground
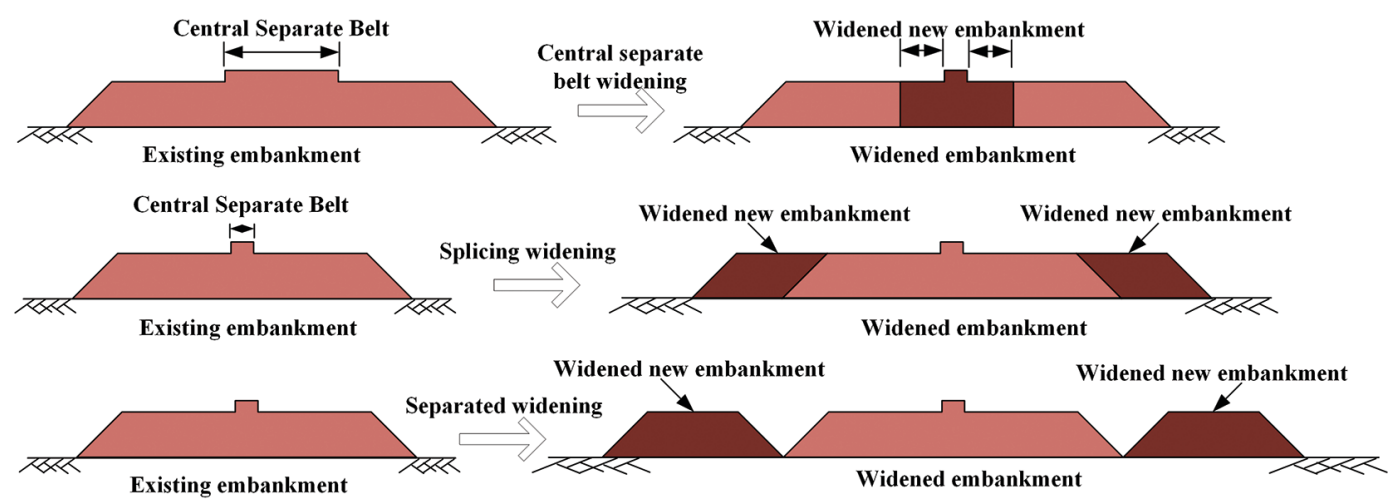

Figure 1. Embankment widening method 


\section{Research progress of embankment separated widening and isolating wall}

There are few cases of separated widening in embankment reconstruction and extension projects in the world. Most of them adopt the combination of splicing widening and separated widening. At present, some typical projects of separated widening in China are listed in Table 1.

Table 1. Typical projects of subgrade separated widening in China

\begin{tabular}{|c|c|c|}
\hline Widening project & $\begin{array}{l}\text { Widening } \\
\text { mileage }\end{array}$ & Widening mode \\
\hline $\begin{array}{l}\text { Shanghai-Nanjing } \\
\text { Expressway }\end{array}$ & $250 \mathrm{~km}$ & $\begin{array}{l}\text { Two sides splicing widening are } \\
\text { the main method, and the local } \\
\text { two sides are separated widening }\end{array}$ \\
\hline $\begin{array}{l}\text { Beijing-Hong Kong-Macao } \\
\text { Expressway } \\
\text { (Shijiazhuang-Cixian } \\
\text { segment) }\end{array}$ & $165 \mathrm{~km}$ & $\begin{array}{l}\text { Two sides splicing widening are } \\
\text { the main method, and the local } \\
\text { two sides are separated widening }\end{array}$ \\
\hline $\begin{array}{l}\text { Lianyungang-Horgos } \\
\text { Expressway } \\
\text { (Tongguan-Weinan segment) }\end{array}$ & $72 \mathrm{~km}$ & $\begin{array}{l}\text { Two sides splicing widening are } \\
\text { the main method, and the local } \\
\text { two sides are separated widening }\end{array}$ \\
\hline Hefei-Nanjing Expressway & $42 \mathrm{~km}$ & $\begin{array}{l}\text { Two sides splicing widening are } \\
\text { the main method, and the local } \\
\text { two sides are separated widening }\end{array}$ \\
\hline $\begin{array}{l}\text { Lianyungang-Horgos } \\
\text { Expressway } \\
\text { (Luoyang-Lingbao segment) }\end{array}$ & 195 km & $\begin{array}{l}\text { One side splicing widening is the } \\
\text { main method, and the local two } \\
\text { sides are separated widening }\end{array}$ \\
\hline
\end{tabular}

For the splicing widening (Figure 1), the settlement influence of new embankment for existing embankment and the effect and mechanism of differential settlement control measures have been discussed through centrifuge model test, full-scale field test, and numerical simulation. For example, Allersma et al. (1994) used the centrifugal model test to show that the widening of embankment on the soft ground causes pavement cracks. Zhang et al. (2011) obtained the tensile strain of geogrid based on the centrifugal model test. They showed that the geogrid reduces the differential settlement and horizontal displacement of new embankment combined with the sensitivity analysis by numerical simulation. A Laboratory physical model test of embankment conducted by Miao et al. (2014) observed that the geogrid application reduces the differential 
settlement by 20-30 mm, which indicates that the geogrid effectively reduces the differential settlement. Zhao et al. (2019) investigated that the total settlement of embankment surface and lateral displacement after embankment construction are significantly reduced when prestressed tubular concrete (PTC) piles and geogrids were used to reinforce embankment. Han et al. (2007) found that the foundation columns play a good control effect on the differential settlement using the elastic-plastic finite element method. The same conclusion was obtained by Kamash \& Han (2014). Yu et al. (2017) adopted a numerical analysis method to consider the influence of the factors on settlement of existing embankment, including layouts of cement-fly ash-gravel (CFG) piles, strengths of CFG piles and filling materials of the new embankment. Their results show that the lightweight filling material has more advantages in reducing the settlement of the existing embankment. Shi et al. (2020) obtained similar conclusions. Using PLAXIS, Jiang et al. (2020) established a finite element model for embankment treatment with prefabricated vertical drains (PVD) and dry jet mixing (DJM) columns in the soft ground of highway widening engineering. It shows that DJM treatment greatly reduces the settlement during construction, the settlement and differential settlement after construction, and the lateral displacement compared to PVD. However, the isolating wall is not involved in the studies mentioned above.

Some researchers have carried out the finite element numerical simulation on isolating wall in the splicing widening of the embankment. However, the separated widening is ignored, such as Wang \& Huang (2011) used the finite element method to compare the effects of four ground and embankment treatment technologies, including geosynthetic reinforcement, lightweight embankment, deep mixed columns and isolating wall. The results show that these treatments reduce the settlement difference and improve stability. Zhang (2011) used the finite element method to analyse the influence of different treatment methods on the deformation of widening embankment in soft ground and obtained the horizontal displacement distribution in the foundation, which provided a theoretical basis for using stress isolation wall to reduce the deformation of existing embankment resulting from the new embankment and indicated that the depth of isolation wall could be determined under the depth of the horizontal displacement concentration zones. Yang et al. (2011) established a two-dimensional elastic-plastic finite element model to reveal the reinforcement mechanism of the isolating wall. The calculation results show that the setting of the isolating wall effectively reduces the horizontal displacement and additional vertical stress to reduce the settlement and differential settlement of the new and existing embankment, and 
the optimal location of the isolating wall is under the new embankment shoulder.

Based on the typical engineering case of the separated widening isolating wall of Xicheng and Huning Expressway, some representative numerical analysis works have been carried out successively, including $\mathrm{Su} \& \mathrm{Xu}(2000)$ applied two-dimensional Biot consolidation nonlinear finite element method to discuss the function of the isolating wall in the separated widening project of Xicheng and Huning Expressway. Duncan-Chang model is used for tangent modulus of soil, and Goodman element, Desai element and rigid plastic thin element are introduced to describe the relative displacement between soil and structure. The analysis shows that the isolating wall effectively reduces the additional settlement of the Huning highway mainline centre after its connection with the Xicheng highway. Xu et al. (1998) also carried out a similar analysis, which reveals the influence of the isolating wall on the subgrade settlement and provides the horizontal displacement and the force distribution on both sides of the isolating wall. To sum up, these finite element numerical simulations ignore the plastic behaviour of soil and the significant deformation effect of soft ground under the embankment load. The influence weight ranking of wall parameters has not been carried out on the differential settlement of the existing embankment, including thickness, depth, location and elastic modulus.

On the other hand, from the perspective of technical specifications, the specifications of China related to highway subgrade, including JTG D30-2015 Specifications for Design of Highway Subgrades, JTG/T 36102019 Technical Specifications for Construction of Highway Subgrades, JTG B01-2014 Technical Standard of Highway Engineering, and JTG/T L11-2014 Guidelines for Design of Expressway Reconstruction and Extension, have specified corresponding allowable value of differential settlement as control standards and proposed some technical guidance measures for splicing widening for reconstruction and extension projects. However, for separated widening, only JTG D30-2015 mentions in principle that when the distance below $20 \mathrm{~m}$ between the new subgrade and the existing subgrade for separated widening, separation measures should be taken to reduce the impact of the new subgrade on the existing subgrade. At the same time, there is a lack of technical guidance for designing and applying the isolating wall. Only the $J T G / T$ D31-02-2013 Technical Guidelines for Design and Construction of Highway Embankment on Soft Ground divides the isolating wall into two categories under its primary functions seepage prevention type and support type. Although some technical requirements are proposed on a structural level, the isolating wall design and corresponding design index systems are still unclear. 


\section{Establishment of finite element model}

\subsection{Problem description and geometric model}

It is assumed that the existing embankment of soft ground is widened by symmetrical separation on both sides. The width of the existing embankment is $26 \mathrm{~m}$, which corresponds to the two-way four-lane expressway in China. The width of the new embankment is $8.5 \mathrm{~m}$ on one side. The height and slope gradient of the new and existing embankment are $4 \mathrm{~m}$ and $1: 1.5$, respectively. A thickness of $10 \mathrm{~m}$ clay is distributed in the ground and a thickness of $5 \mathrm{~m}$ dense sand under it. To reduce the impact of the widening new embankment on the existing embankment, an isolating wall with a depth of $D_{W}$ and a thickness of $T_{W}$ is set in the subgrade between the new and existing embankment for treatment, and the distance between the centre of the isolating wall and the centreline of the existing embankment is $L_{W}$.

The depth of the isolating wall $\left(D_{W}\right)$ is $10 \mathrm{~m}$, the thickness $\left(T_{W}\right)$ is $1 \mathrm{~m}$, and the distance $\left(L_{W}\right)$ is $17 \mathrm{~m}$. The right half of the structure is taken as a plane strain problem to construct a numerical model considering the symmetry of the structure. When the model is established, the coordinate origin is taken at the intersection of the ground surface and the centerline of the existing embankment. The positive directions of the $X$-axis and $Y$-axis are defined as the horizontal right and vertical up, respectively. To avoid the influence of boundary conditions as much as possible, the size of the model along the $X$ direction is $100 \mathrm{~m}$.

\subsection{Constitutive model and material parameters}

To overcome the defects of the Mohr-Coulomb model, better simulate the influence of the average effective stress reduction in the process of undrained loading, and more genuinely reflect the stability of soft soil in the separated widening project, the advanced Soft Soil Creep model is adopted for clay, and the material type is undrained. The ideal elastic-plastic Mohr-Coulomb model is adopted for the new and existing embankment filling and dense sand, and it is regarded as drained material. Particular attention should be paid to the different values of the horizontal and vertical permeability coefficients of the clay to consider the anisotropy of clay permeability, and consider the change 
of the permeability coefficient of the clay in the consolidation and compaction process under Equation (1).

$$
\log \left(\frac{k}{k_{0}}\right)=\frac{\Delta e}{c_{k}}
$$

where $\Delta e=e-e_{0} ; e_{0}$ is the initial porosity; $e$ is the porosity after consolidation; $k_{0}$ is the initial permeability coefficient; $k$ is the permeability coefficient after consolidation; $c_{k}$ is a constant, generally half of the initial porosity, that is, $c_{k}=0.5 e_{0}$.

For dense sand and embankment filling, they are regarded as drained materials, and the permeability coefficient is higher than that of clay, and the value of $c_{k}$ is high enough, i.e., the permeability coefficient is assumed to be constant. The specific parameters are shown in Table 2. The isolating wall is simulated by solid replacement. It is considered linear elasticity, and the material type is undrained, and its permeability coefficient is reduced by order of magnitude compared to clay to reflect its impermeability. The parameters are shown in Table 3.

Table 2. Soil material parameters (Brinkgreve, 2002; Jiang et al., 2015)

\begin{tabular}{|c|c|c|c|c|c|}
\hline Name & Unit & Dense Sand & Clay & $\begin{array}{c}\text { Existing } \\
\text { embankment }\end{array}$ & $\begin{array}{c}\text { New } \\
\text { embankment }\end{array}$ \\
\hline Material model & - & Mohr-Coulomb & Soft Soil Creep & Mohr-Coulomb & Mohr-Coulomb \\
\hline Material behaviour & - & Drained & Undrained & Drained & Drained \\
\hline$E_{1}$ & $\mathrm{MPa}$ & 60.0 & - & 13.0 & 15.0 \\
\hline$c_{1}$ & $\mathrm{kPa}$ & 1.0 & 8.0 & 32.0 & 31.0 \\
\hline$\varphi$, & $\circ$ & 38.0 & 24.0 & 24.0 & 25.0 \\
\hline$v$ & - & 0.33 & 0.15 & 0.15 & 0.3 \\
\hline$\lambda^{*}$ & - & - & 0.035 & - & - \\
\hline$\kappa^{*}$ & - & - & 0.007 & - & - \\
\hline$\mu^{*}$ & - & - & 0.002 & - & - \\
\hline$K_{0}{ }^{\mathrm{NC}}$ & - & - & 0.59 & - & - \\
\hline$\gamma_{\text {unsat, }}$ & $\mathrm{kN} / \mathrm{m}^{3}$ & 21.5 & 15.0 & 15.0 & 19.0 \\
\hline$\gamma_{s a t,}$ & $\mathrm{kN} / \mathrm{m}^{3}$ & 22.0 & 18.0 & 18.0 & 20.0 \\
\hline$k_{x 1}$ & $\mathrm{~m} / \mathrm{d}$ & 1.0 & $4.0 \cdot 10^{-4}$ & 1.0 & 1.0 \\
\hline$k_{v_{1}}$ & $\mathrm{~m} / \mathrm{d}$ & 1.0 & $3.0 \cdot 10^{-4}$ & 1.0 & 1.0 \\
\hline$e_{0}$ & - & 0.5 & 0.5 & 0.5 & 0.5 \\
\hline$c_{k}$ & - & $1.0 \cdot 10^{15}$ & 0.7 & $1.0 \cdot 10^{15}$ & $1.0 \cdot 10^{15}$ \\
\hline$R_{\text {inter }}$ & - & 1.0 & 0.5 & 1.0 & 1.0 \\
\hline
\end{tabular}

Note: $K_{0}{ }^{\mathrm{NC}}$ is the lateral stress coefficient; $\mu^{*}$ is the secondary compression index; $\lambda^{*}$ is the modified compression index; $\kappa^{*}$ is the modified expansion index. 
Table 3. Linear elastic model parameters of isolating wall

\begin{tabular}{cccccc}
\hline $\begin{array}{c}\boldsymbol{E}, \\
\mathrm{MPa}\end{array}$ & $v$ & $\gamma_{\boldsymbol{\prime}}$ & $\boldsymbol{k}_{\boldsymbol{x} \mathbf{\prime}}$ & $\boldsymbol{k}_{\mathrm{v}}$ & $\boldsymbol{R}_{\text {inter }}$ \\
\hline 200.0 & - & $\mathbf{k N} / \mathbf{m}^{\mathbf{3}}$ & $\mathbf{m} / \mathbf{d}$ & $\mathbf{m} / \mathbf{d}$ & - \\
\hline
\end{tabular}

\subsection{Element type selection and mesh generation}

A 15-node triangular element is adopted to discretise soil and isolating wall containing 12 stress points to get accurate calculation results. The global mesh density is set as "medium" during mesh generation, and the wall replacement area is densified again to get more accurate calculation results. At the same time, to scientifically simulate the interaction between the wall and the surrounding soil, the interface is set up between the wall and the soil by using the interface function embedded in PLAXIS. The interface is composed of interface elements. When the 15-node soil element is used, the corresponding interface element is defined by five groups of nodes (Figure 2), which has a limited thickness. However, the coordinates of each node pair are identical in the calculation formulation of PLAXIS, i.e., zero thickness element. It is necessary to set a virtual thickness value (virtual thickness $=$ virtual thickness factor $\times$ average element size) to define the properties of interface materials. The higher the value is, the more elastic deformation is generated. Generally, it is assumed that the deformation of the interface element is minimal, so the virtual thickness is also minimal. If and only if it is under large normal stress, it needs to be appropriately adjusted. The default value of the virtual thickness factor is 0.1 .

The elastic-plastic constitutive model is used to describe the interface properties. The stress transfer between the wall and the soil depends on the interface strength. The interface strength is calculated as the strength of the surrounding soil times the friction coefficient $R_{\text {inter }}$ of the soil and the isolating wall, that is to say, the degree of interaction among the two is reflected by $R_{\text {inter }}$ as shown in Equations (2) and (3):

$$
\begin{aligned}
c_{\text {inter }} & =R_{\text {inter }} c_{\text {soil }}, \\
\tan \varphi_{\text {inter }} & =R_{\text {inter }} \tan \varphi_{\text {soil }},
\end{aligned}
$$

When there is no relative sliding between the wall and the surrounding soil and the deformation is the same, $R_{\text {inter }}=1$ is taken; when there is a tendency of relative sliding, the strength of the interface element is less than that of the surrounding soil, $R_{\text {inter }}<1$ is taken; in this 
calculation, considering the relative sliding between the wall and the soft soil and the low strength of the interface, the $R_{\text {inter }}=0.5$ is taken.

In the PLAXIS program, the elastic-plastic mechanical properties of the interface elements are calculated under the Mohr-Coulomb criterion: the displacement is minimal in the elastic range; when entering the plastic state, a permanent sliding surface can be generated. Equation (4) is expressed as follows:

$$
|\tau| \leq \sigma_{n} \tan \varphi_{\text {inter }}+c_{\text {inter' }}
$$

where $\tau$ is the shear stress; $\sigma_{n}$ is the normal stress acting on the interface element; $\varphi_{\text {inter }}$ and $c_{\text {inter }}$ are the friction angle and cohesion of the interface element, respectively.

\subsection{Boundary conditions}

The left side of the model is the axis of symmetry. Its horizontal displacement is zero, and it is impermeable. So, the displacement boundary with constrained horizontal displacement and free vertical displacement and closed consolidation boundary are set. The same is true for the right side of the model. The horizontal and vertical displacements of the bottom of the model are both constrained. Due to the dense sand soil, the consolidation boundary is open type (i.e., permeable). The upper surface of the model is free. The numerical model is shown in Figure 2.

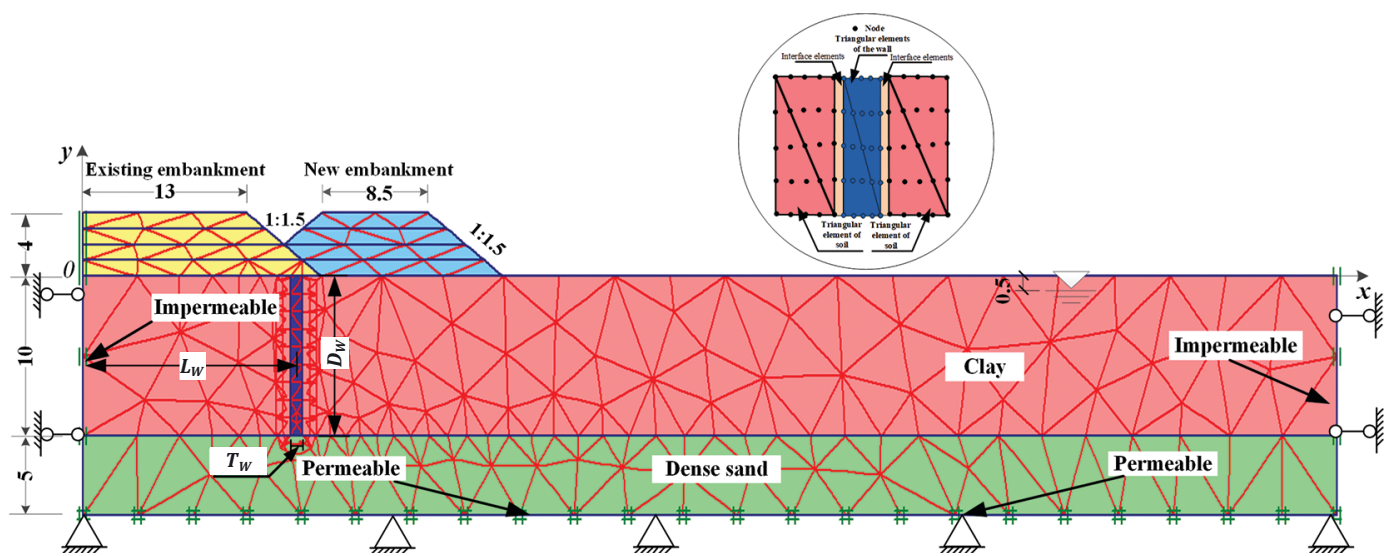

Note: units in $\mathrm{m}$.

Figure 2. Numerical model 


\subsection{Initial conditions and construction simulation}

The groundwater level is set at $0.5 \mathrm{~m}$ below the ground surface, i.e., $y=-0.5 \mathrm{~m}$. After the geometric model is created and the finite element mesh is divided, the initial stress state is generated, including the initial hydrostatic pressure and the initial effective stress field. The initial effective stress field is generated by the process of $K_{0}$ because the ground surface and groundwater level are both horizontal.

The new and existing embankment construction is simulated using the "staged-construction" function of PLAXIS software. The existing embankment is filled in four layers, the thickness of each layer is $1.0 \mathrm{~m}$, the construction time of each layer is $20 d$, the construction interval of each layer after a filling is $30 d$. The existing embankment is widened after ten years of in-service. The new embankment still adopts the filling mode of the existing embankment. To conveniently obtain the settlement disturbance of the existing embankment only by the new embankment filling, the existing displacement field is cleared when the first layer of the new embankment is filled, that is to activate the option of "reset displacement to zero" in PLAXIS, and the isolating wall is constructed by solid replacement at the same time. Pursuant to the JTG B01-2014, the calculation is terminated after completing the fourth layer filling of the new embankment and the interval of 15 years (i.e., the corresponding design service life of the expressway asphalt pavement structure is 15 years). Figure 3 presents the construction process.

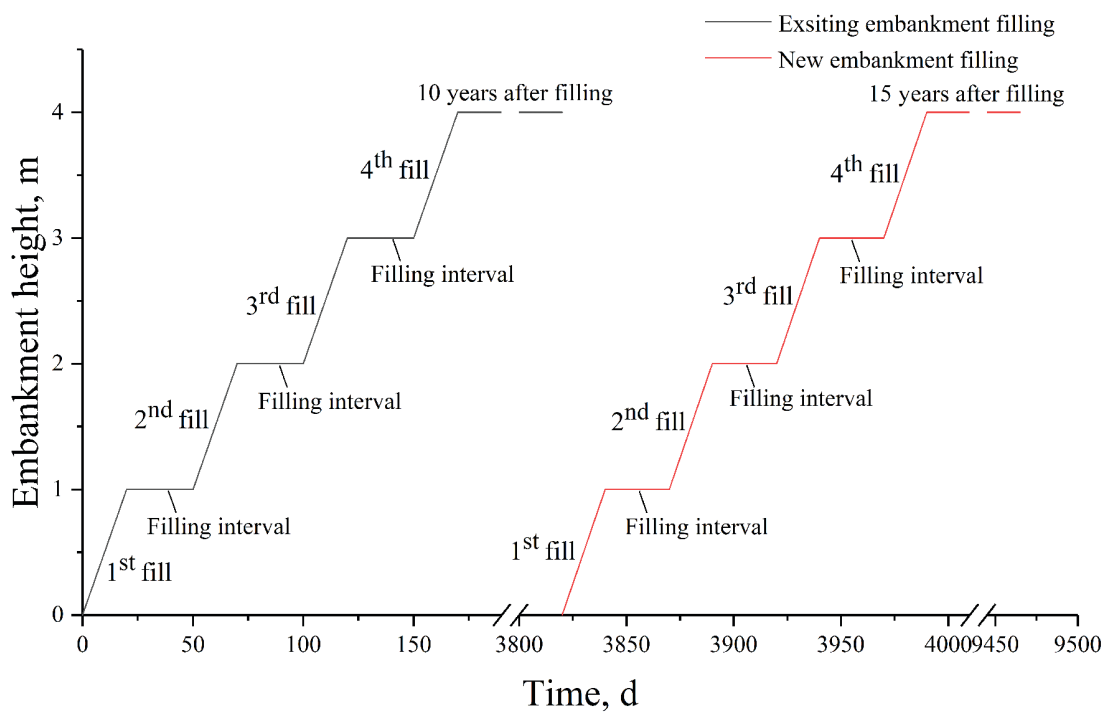

Figure 3. Construction process
Design Optimisation Analysis of Isolating Wall for Separated Widening

Embankment on Soft Ground 


\subsection{Geometric nonlinear simulation}

Considering that the soft ground has high compressibility and produces large settlement, part of the soil initially above the groundwater level will settle below the groundwater level after the consolidation settlement. Due to the buoyancy of the water, the effective weight of the soil that settles below the groundwater level decreases, resulting in the decrease of the effective load and settlement value with time. Therefore, the advanced functions of "updated mesh" and "updated water pressure" embedded in PLAXIS are activated. That is, a nonlinear geometric effect is considered.

\section{Discussion on the mechanical response}

\subsection{Effect on lateral displacement}

The analysis model without an isolating wall is established when the soil within the area of isolating wall is non-replacement, the interface element is de-activated, and the other conditions are the same in the above numerical model calculation process. Figure 4 shows the lateral displacement distribution diagram after 15 years of embankment

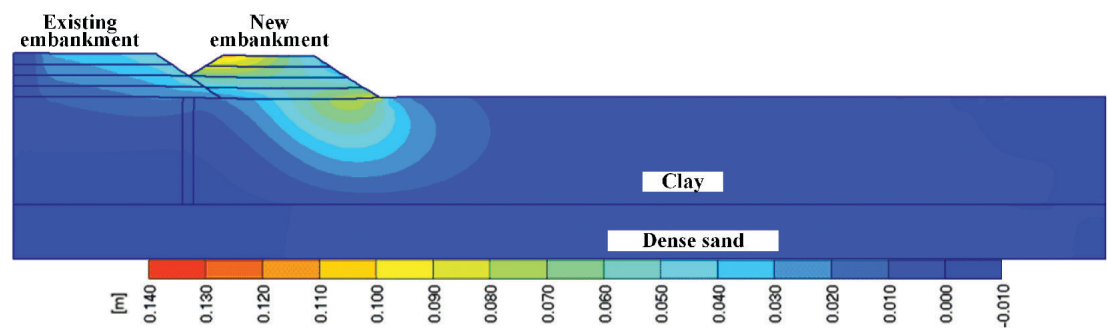

a) without isolating wall

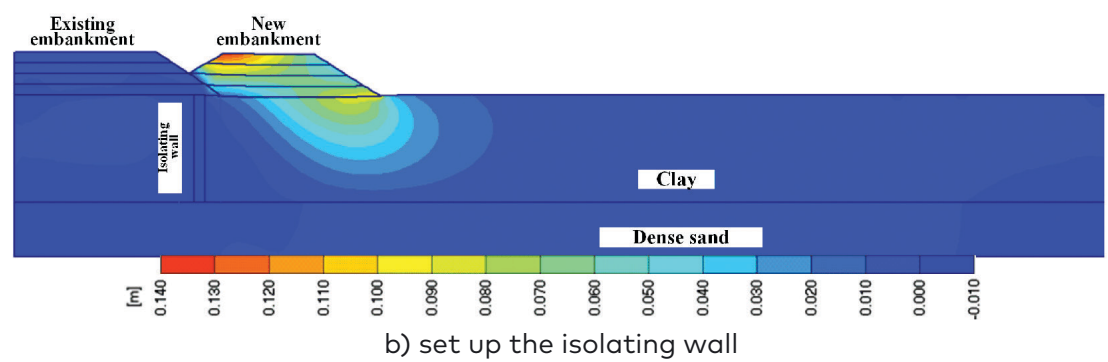

Figure 4. Lateral displacement distribution after 15 years of embankment widening 
widening with or without an isolating wall. It can be seen from Figure $4 \mathrm{a}$ that when the new embankment is widened and constructed beside the existing embankment, compared to the existing embankment, the new embankment causes consolidation settlement under the action of self-weight. The new embankment foundation settlement has a particular drag effect on the existing embankment foundation so that the existing embankment has a large lateral displacement. It can be seen from Figure $4 \mathrm{~b}$ that the setting of the isolating wall has a good constraint on the lateral displacement of the existing embankment and the existing embankment foundation, but has a little constraint on the lateral displacement of the new embankment, which indicates that the corresponding engineering measures still need to be taken based on the setting of the isolating wall to control of the lateral displacement of the new embankment in the practical project.

\subsection{Effect on vertical settlement}

Figure 5 shows the distribution of vertical settlement after 15 years of embankment widening with or without an isolating wall. Figure $5 \mathrm{a}$ presents that when the new embankment is widened and constructed beside the existing embankment, compared to the existing embankment, the construction of the new embankment generates additional stress

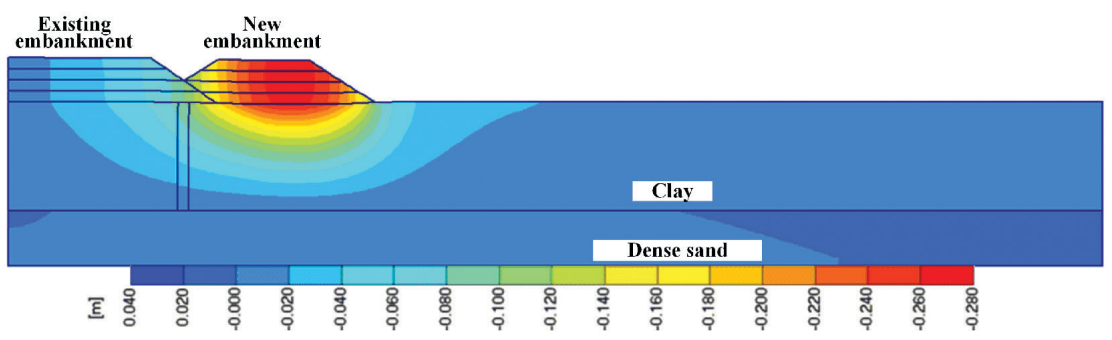

a) without isolating wall

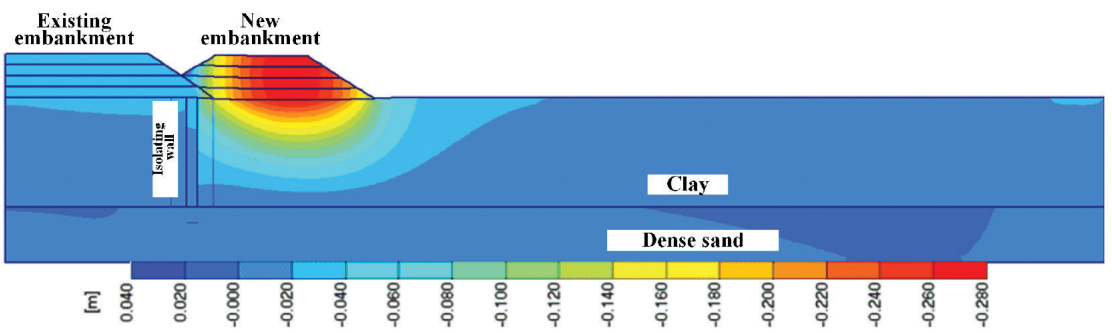

b) set up the isolating wall
Xin Jiang,

Yongguo Fu,

Linyu Li,

Hanyan Gu,

Yanjun Qiu

Design Optimisation Analysis of Isolating Wall for Separated

Widening

Embankment on Soft Ground

Figure 5. Vertical displacement distribution after 15 years of embankment widening 
that causes the reconsolidation settlement of the existing embankment foundation. Moreover, there is a difference in distance between the existing embankment surface and the new embankment, which inevitably leads to the vertical settlement of the side close to the new embankment larger than that far away from the new embankment. Figure $5 b$ indicates that the setting of the isolating wall cuts off the additional stress transfer well, reduces the vertical settlement impact of the widening new embankment for the existing embankment, and keeps the overall vertical settlement of the existing embankment relatively uniform and small. However, the vertical settlement of the new embankment only acts on the side close to the existing embankment. It has little effect on the new embankment far away from the existing embankment. This also confirms that the corresponding engineering measures should be adopted to control the vertical settlement of the new embankment combined with the isolating wall in the practical project.

\subsection{Effect on excess pore water pressure}

Considering the influence of whether to set up the isolating wall on the excess pore water pressure, the cloud diagram of the calculation result of the excess pore water pressure in the PLAXIS software is

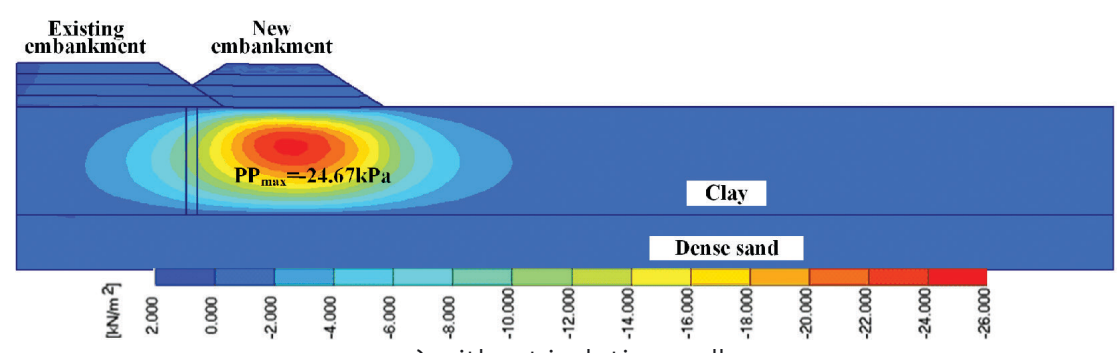

a) without isolating wall

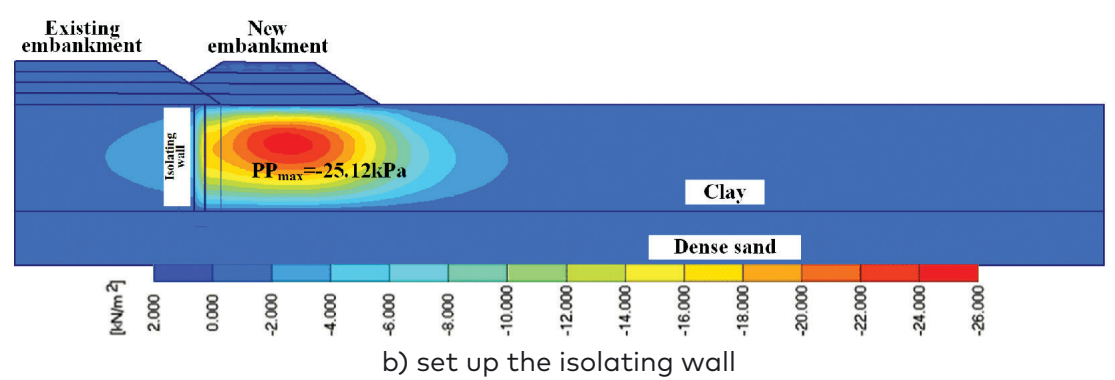

Figure 6. Excess pore water pressure distribution during the construction period 
output during the construction period of the widening new embankment (i.e., when the fourth layer is completed), whose calculation result of pressure is negative, as shown in Figure 6. Pursuant to the comparison of Figure $6 \mathrm{a}$ and Figure $6 \mathrm{~b}$, the setting of the isolating wall has a relatively more significant impact on the excess pore water pressure in the foundation of the existing embankment, which significantly reduces the excess pore water pressure. For the widening of a new embankment, due to the impermeability of the isolating wall, the excess pore water pressure near the isolating wall increases in the foundation of the widened new embankment. However, it has little effect on the excess pore water pressure from the existing embankment side to the widen new embankment foundation. At the same time, it can be known that the setting of the isolating wall has relatively little effect on the maximum excess pore water pressure $\left(P P_{\max }\right)$ and its location during the construction period.

\section{Weight analysis on settlement disturbance of existing embankment}

\subsection{Effect analysis of core design parameters of isolating wall}

\subsubsection{Effect of the location}

Considering the difference between the location $\left(L_{W}\right)$ of the isolating wall and the other design parameters of the isolating wall on the settlement of the existing embankment, the influence rule of the location of the isolating wall is analysed firstly. Figure $7 \mathrm{a}$ and Figure $7 \mathrm{~b}$ show that in the process of the isolating wall moving from the existing embankment shoulder to the new embankment shoulder (13 m-19 m), the overall vertical settlement of the existing embankment increases. When $L_{W}=17 \mathrm{~m}$, the overall vertical settlement of the existing embankment is the most uniform. That is, the differential settlement is the smallest. In the practical engineering design, this location should be considered firstly. When the wall is set close to the surface of the existing embankment, namely $L_{W}=13 \mathrm{~m}$, there is an obvious mutation point in the settlement curve, indicating a stronger interaction between the wall and the soil. The vertical displacement of the wall drives the soil settlement. In the practical project, the setting of the isolating wall close to the embankment surface of the existing road should be avoided. 


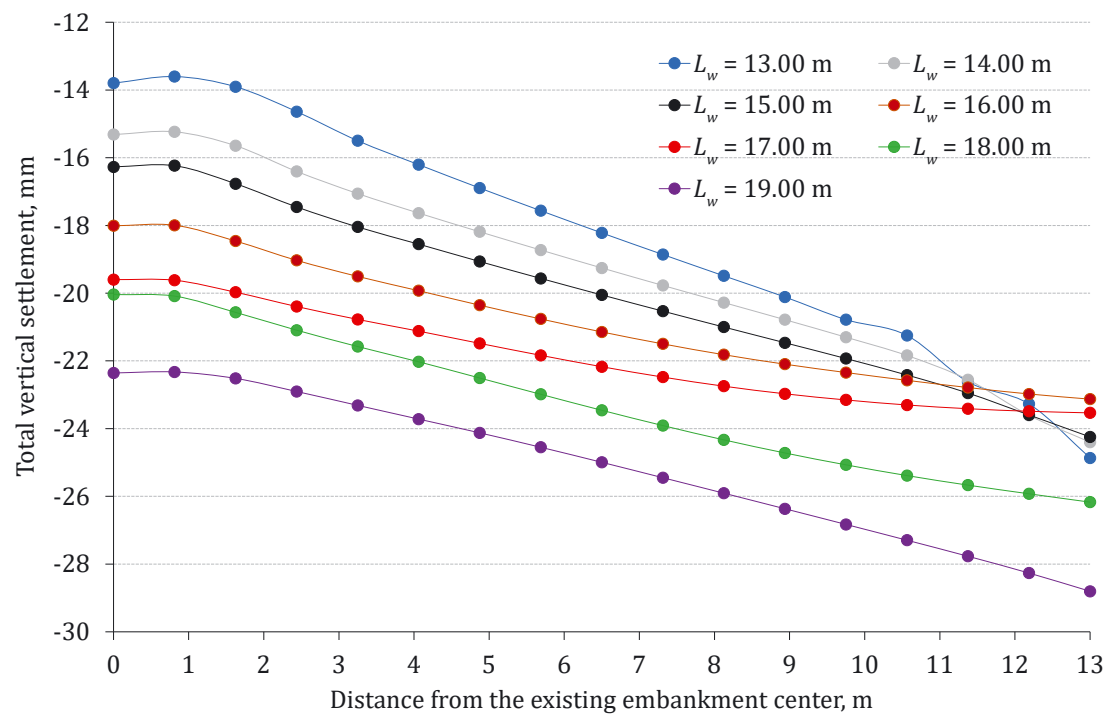

a) vertical settlement

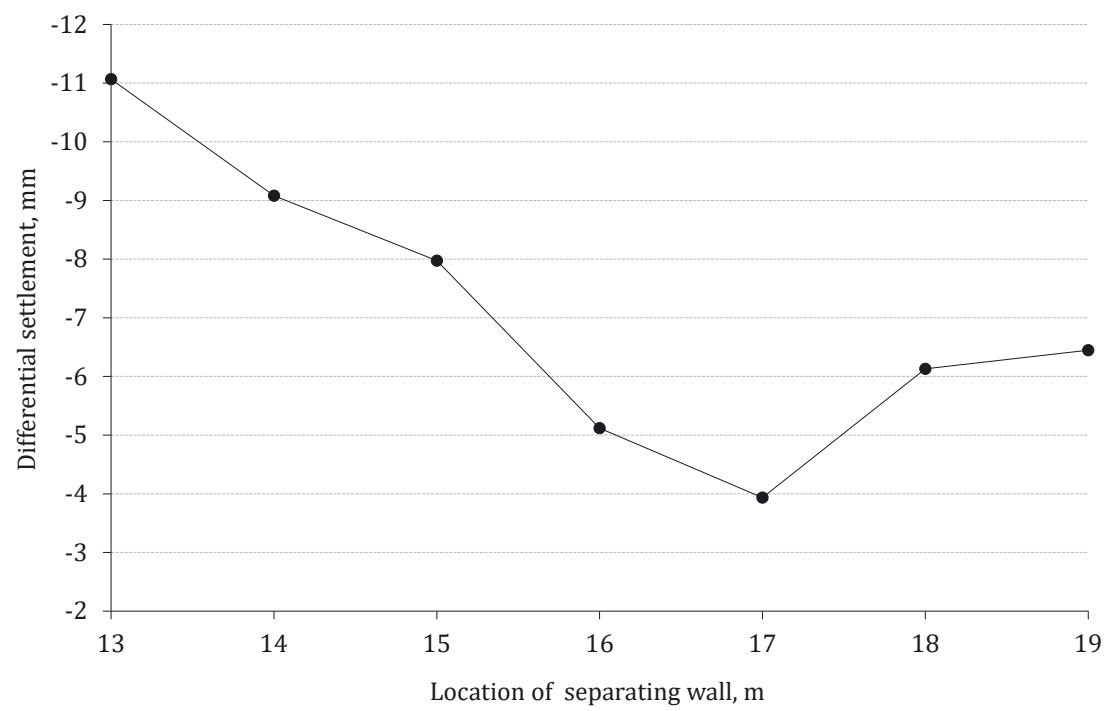

b) differential settlement

Figure 7. Effect of the location 


\subsubsection{Effect of the depth, thickness and elastic modulus}

The design parameters of the isolating wall itself include depth $\left(D_{W}\right)$, thickness $\left(T_{W}\right)$ and elastic modulus $\left(E_{W}\right)$. The wall is firstly set at the recommended location (i.e., $L_{W}=17 \mathrm{~m}$ ) as discussed above. Consequently, the influence rules of the three design parameters are sorted out respectively. It can be seen from Figure 8 that the influence of the depth $\left(D_{W}\right)$, thickness $\left(T_{W}\right)$ and elastic modulus $\left(E_{W}\right)$ of the isolating wall shows the same rule on the settlement of the existing embankment. With the increase of the depth $\left(D_{W}\right)$, thickness $\left(T_{W}\right)$ and elastic modulus $\left(E_{W}\right)$, the maximum settlement value decreases. At the same time, the overall settlement of the existing embankment tends to be uniform, the differential settlement decreases. However, when the depth $\left(D_{W}\right)$, thickness $\left(T_{W}\right)$ and elastic modulus $\left(E_{W}\right)$ increase to a certain value, the continuous increase of the value has little effect on the settlement control of the existing embankment. Moreover, suppose the value is too high, in that case, the shoulder settlement is smaller than that of the road centre, which results in forming the reverse slope of the existing embankment and affects driving safety.

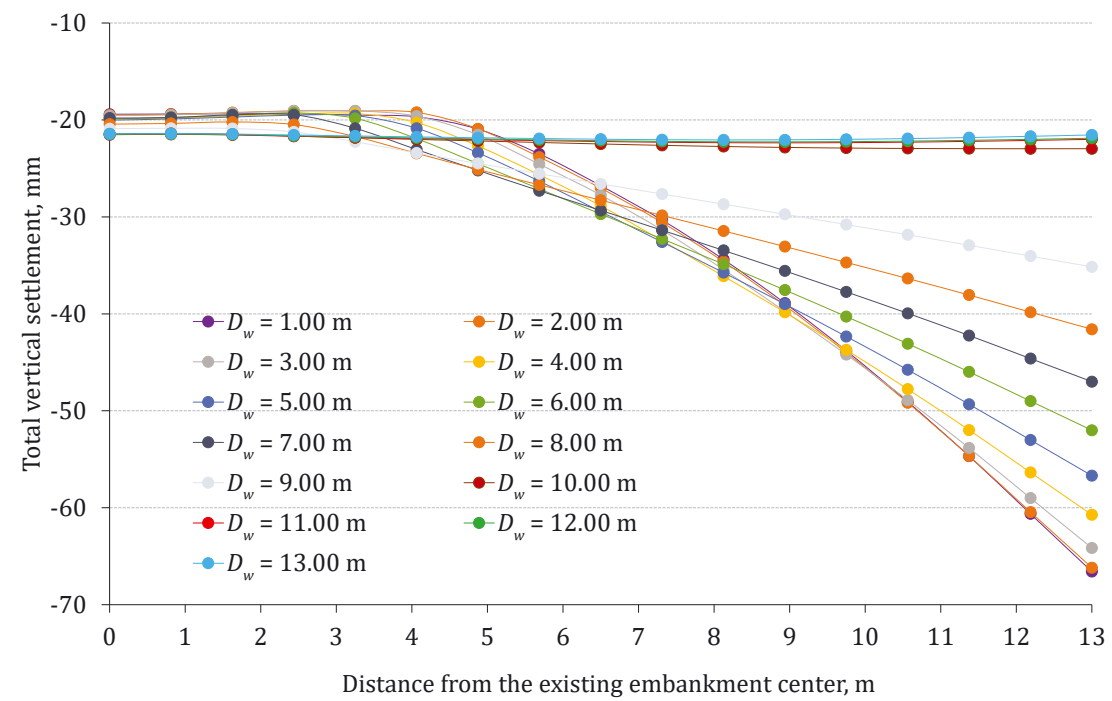

a) wall depth $\left(D_{W}\right)$
Design Optimisation Analysis of Isolating Wall for Separated Widening

Embankment on Soft Ground 


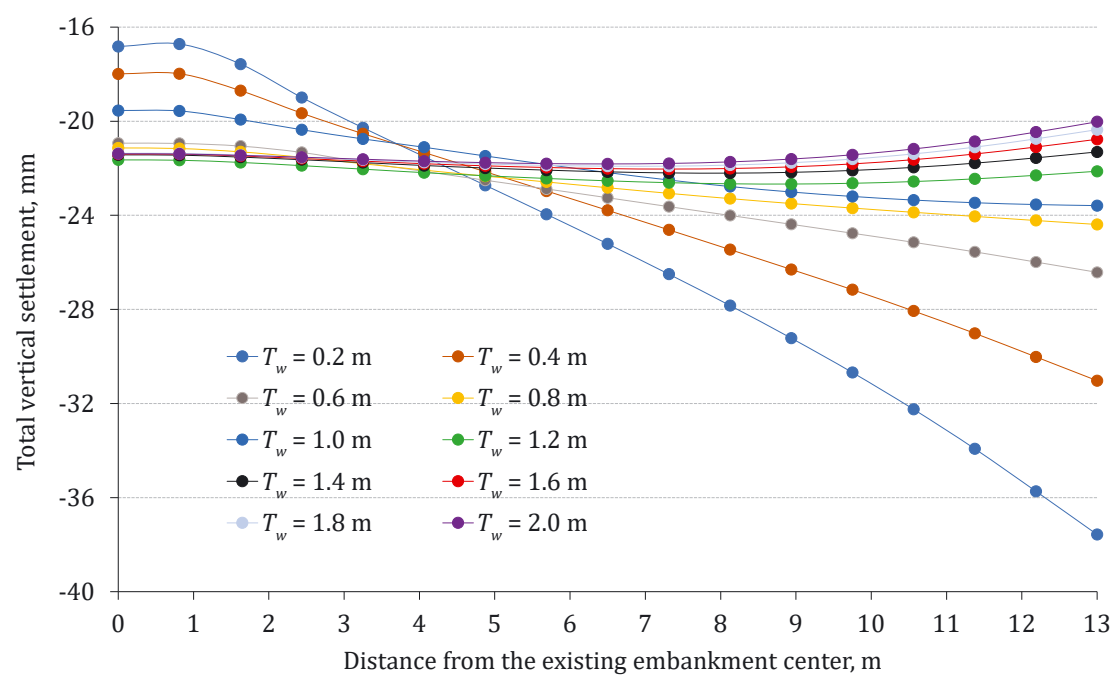

b) wall thickness ( $\left.T_{w}\right)$

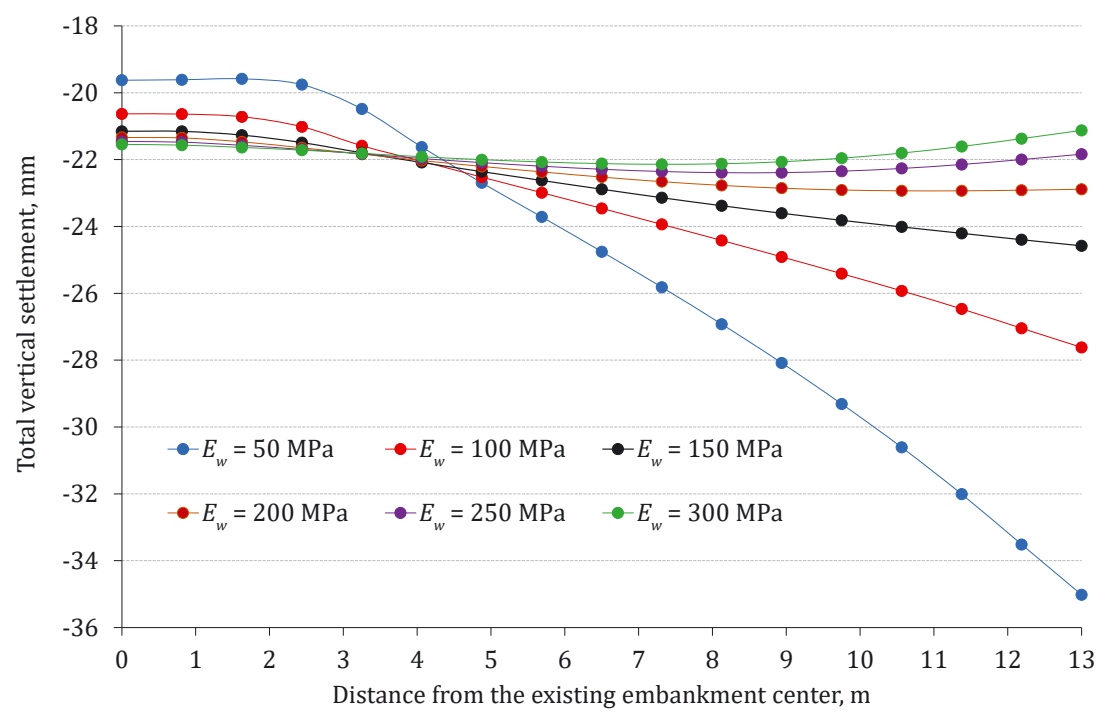

c) elastic modulus of wall $\left(E_{W}\right)$

Figure 8. Effect of the depth $\left(D_{W}\right)$, thickness $\left(T_{W}\right)$ and elastic modulus $\left(E_{W}\right)$ 


\subsection{Weight rank analysis of core design parameters of the isolating wall}

Based on the differential settlement control of the existing embankment, using Minitab orthogonal experiment software, the isolating wall parameters, including location $\left(L_{W}\right)$, thickness $\left(T_{W}\right)$, depth $\left(D_{W}\right)$, and elastic modulus $\left(E_{W}\right)$ are orthogonally tested to determine the influence weight rank and then guide the practical engineering design.

The location $\left(L_{W}\right)$, thickness $\left(T_{W}\right)$, depth $\left(D_{W}\right)$ and elastic modulus $\left(E_{W}\right)$ of the isolating wall are divided into five levels, respectively, as shown in Table 4. Therefore, the orthogonal experiment design is $L 25\left(5^{4}\right)$, and the number of experiments is 25 .

Table 4. Grade level division of the isolating wall parameters

\begin{tabular}{ccccc}
\hline Level & $\begin{array}{c}\text { Location } \\
\left(L_{w}\right), \mathbf{m}\end{array}$ & $\begin{array}{c}\text { Thickness } \\
\left(\boldsymbol{T}_{\boldsymbol{w}}\right) \mathbf{m}\end{array}$ & $\begin{array}{c}\text { Depth } \\
\left(\boldsymbol{D}_{\boldsymbol{w}}\right) \mathbf{m} \mathbf{m}\end{array}$ & $\begin{array}{c}\text { Elastic modulus } \\
\left(\boldsymbol{E}_{w}\right), \mathbf{M P a}\end{array}$ \\
\hline 1 & 14 & 0.2 & 4 & 50 \\
2 & 15 & 0.6 & 6 & 100 \\
3 & 16 & 1.0 & 8 & 150 \\
4 & 17 & 1.4 & 10 & 200 \\
5 & 18 & 1.8 & 12 & 250 \\
\hline
\end{tabular}

By using the range analysis method to analyse the orthogonal experiment, the range analysis results of the location $\left(L_{W}\right)$, thickness $\left(T_{W}\right)$, depth $\left(D_{W}\right)$ and elastic modulus $\left(E_{W}\right)$ of the isolating wall is obtained on the differential settlement of the existing embankment, as shown in Table 5.

Table 5. Orthogonal experiment range analysis data

\begin{tabular}{ccccc}
\hline Level & $\begin{array}{c}\text { Location } \\
\left(L_{w}\right), \mathbf{m}\end{array}$ & $\begin{array}{c}\text { Thickness } \\
\left(\boldsymbol{T}_{w}\right), \mathbf{m}\end{array}$ & $\begin{array}{c}\text { Depth } \\
\left(\boldsymbol{D}_{w}\right), \mathbf{m}\end{array}$ & $\begin{array}{c}\text { Elastic modulus } \\
\left(\boldsymbol{E}_{w}\right), \mathbf{M P a}\end{array}$ \\
\hline 1 & 23.423 & 27.909 & 41.964 & 28.241 \\
2 & 23.249 & 24.091 & 35.136 & 22.694 \\
3 & 21.451 & 24.236 & 24.422 & 21.558 \\
4 & 25.322 & 23.693 & 9.567 & 24.237 \\
5 & 27.988 & 21.505 & 10.345 & 24.703 \\
Delta $^{*}$ & 6.537 & 6.404 & 32.396 & 6.683 \\
Rank & 3 & 4 & 1 & 2 \\
\hline
\end{tabular}

Note: *the highest average response characteristic value minus the lowest average response characteristic value for levels of that factor.
Design Optimisation Analysis of Isolating Wall for Separated Widening

Embankment on Soft Ground 
Pursuant to the data in Table 5, the "rank" values corresponding to the location $\left(L_{W}\right)$, thickness $\left(T_{W}\right)$, depth $\left(D_{W}\right)$ and elastic modulus $\left(E_{W}\right)$ of the isolating wall are 3, 4, 1 and 2, respectively, which indicates that the influence weight rank of the location $\left(L_{W}\right)$, thickness $\left(T_{W}\right)$, depth $\left(D_{W}\right)$ and elastic modulus $\left(E_{W}\right)$ of the isolating wall on the differential settlement of the existing embankment is depth $\left(D_{W}\right)$ above elastic modulus $\left(E_{W}\right)$ above location $\left(L_{W}\right)$ above thickness $\left(T_{W}\right)$. In the practical separated widening project, when the isolating wall is adopted to control the differential settlement of the existing embankment, the depth $\left(D_{W}\right)$ of the isolating wall should be given priority.

\section{Conclusions and recommendations}

1. In the whole process of the separated widening project, the isolating wall effectively reduces the settlement disturbance to the existing embankment and ensure the normal operation of the existing embankment. The settlement control of widening new embankment only acts on the side close to the existing embankment but has little effect on the side far away from the existing embankment. Therefore, the corresponding engineering treatment measures should be taken for the new embankment based on the treatment of the isolating wall.

2. In the practical project, due to the interaction between the wall and the soil, the vertical displacement of the wall drives the settlement of the soil. It then aggravates the differential settlement of the existing embankment surface. Therefore, the isolating wall should be avoided to be set close to the existing embankment surface. At the same time, there is an optimal location between the shoulders of the new and existing embankment, which makes the vertical settlement of the existing embankment the most uniform. That is, the differential settlement is the least. In the practical engineering design, this location should be given priority.

3. With the increase of the depth, thickness, and elastic modulus of the isolating wall, the maximum settlement decreases, and the overall settlement of the existing embankment tends to be uniform. That is, the differential settlement decreases. When the depth, thickness and elastic modulus are increased to a certain value, the further increase of the value has little effect on the settlement control of the existing embankment. Moreover, suppose the value is too high, in that case, the settlement of the existing shoulder is smaller than that of the existing road 
centre, and the formation of the reverse slope affects driving safety. Therefore, the depth, thickness and elastic modulus of the isolating wall need to be reasonably designed in the practical project.

4. Based on the differential settlement control of the existing embankment, the effect weight rank of the location, depth, thickness and elastic modulus of the isolating wall are obtained as follows: depth above elastic modulus above location above thickness. In the practical project, the reasonable depth of the wall is designed firstly.

\section{Acknowledgements}

The authors thank the Sichuan Science and Technology Program and Key Laboratories Open Engineering Practice Program to Undergraduates of SWJTU for providing the funding for this work.

\section{Funding}

This work was supported by Sichuan Science and Technology Program under Grant No. 2019YFS0492 and Key Laboratories Open Engineering Practice Program to Undergraduates of SWJTU under Grant No. ZD2020010010.

\section{REFERENCES}

Allersma, H. G. B., Ravenswaay, L., \& Vos, E. (1994). Investigation of road widening on soft soils using a small centrifuge. Transportation Research Record, 1462, 47-53.

Brinkgreve, R. B. J. (2002). PLAXIS Version 8 Material Models Manual. Delft University of Technology \& PLAXIS b.v., The Netherlands.

Habib, H. A. A., Brugman, M. H. A., \& Uijting, B. G. J. (2002, September). Widening of Road N247 founded on a geogrid reinforced mattress on piles. In Proc., 7th Int. Conf. on Geosynthetics (pp. 369-372). Nice, France: Swets \& Zeitlinger.

Han, J., Oztoprak, S., Parsons, R. L., \& Huang, J. (2007). Numerical analysis of foundation columns to support widening of embankments. Computers and Geotechnics, 34(6), 435-448. https://doi.org/10.1016/j.compgeo.2007.01.006

He, L. D., Xu, Z. Z., Ma, X. H., He, P., Chen, X. T., \& Zhou, M. W. (1998a). The application of high pressure jet grouting method in the settlement isolating wall project. Advances in Science and Technology of Water Resources, 18(2), 55-57. (in Chinese) 
He, L. D., Xu, Z. Z., Ma, X. H., He, P., Chen, X. T., \& Zhou, M. W. (1998b). Quality inspection and evaluation of settlement isolation wall of Xicheng-Huning Expressway. Advances in Science and Technology of Water Resources, 18(2), 58-60. (in Chinese)

Jia, N., Chen, R. P., Chen, Y. M., Xu, L. X., \& Yang, S. H. (2004). Theoretical analysis and measurement for widening project of Hang-Yong Expressway. Chinese Journal of Geotechnical Engineering, 26(6), 755-760. https://doi.org/10.3321/j.issn:1000-4548.2004.06.006 (in Chinese)

Jiang, X., Jiang, Y., Liang, X. J., Wu, C. Y., \& Qiu, Y. J. (2015). Numerical simulation on deformation behaviors for widened expressway embankment over soft ground. Journal of Railway Science and Engineering, 12(5), 1039-1046. https://doi.org/10.3969/j.issn.1672-7029.2015.05.009 (in Chinese)

Jiang, X., Jiang, Y., Wu, C. Y., Wang, W. Q., Geng, J. Y., \& Qiu, Y. J. (2020). Numerical analysis for widening embankments over soft soils treated by PVD and DJM columns. International Journal of Pavement Engineering, 21(3), 267-279. https://doi.org/10.1080/10298436.2018.1461869

JTG B01-2014 Technical Standard of Highway Engineering (in Chinese)

JTG D30-2015 Specifications for Design of Highway Subgrade (in Chinese)

JTG/T 3610-2019 Technical Specifications for Construction of Highway Subgrade (in Chinese)

JTG/T D31-02-2013 Technical Guidelines for Design and Construction of Highway Embankment on Soft Ground (in Chinese)

JTG/T L11-2014 Guidelines for Design of Expressway Reconstruction and Extension (in Chinese)

Kamash, W. E., \& Han, J. (2014). Displacements of column-supported embankments over soft clay after widening considering soil consolidation and column layout: Numerical analysis. Soils and Foundations, 54(6), 1054-1069. https://doi.org/10.1016/j.sandf.2014.11.002

Liu, Z. J. (2001). Geometric design of American highway (I). Journal of Foreign Highway, 21(2), 1-6. https://doi.org/10.3969/j.issn.1671-2579.2001.03.001 (in Chinese)

Lu, W., Miao, L., Wang, E., Zhang, J., Zhang, Y., \& Wang, H. (2020). A case study on geogrid-reinforced and pile-supported widened highway embankment. Geosynthetics International, 27(3), 261-274. https://doi.org/10.1680/jgein.19.00024

Ludlow, S., Chen, W. F., Bourdeau, P. L., \& Lovell, C. W. (1992). Embankment widening and grade raising on soft foundation, FHWA-IN-JHRP-91-18. Purdue University, West Lafayette, IN, USA.

Miao, L., Wang, F., Han, J., \& Lv, W. (2014). Benefits of geosynthetic reinforcement in widening of embankments subjected to foundation differential settlement. Geosynthetics International, 21(5), 321-332.

https://doi.org/10.1680/gein.14.00019

Nie, P., Qu, X. J., Liu, F. Q., Cong, L., \& Guo, Z. Y. (2005). Allowable differential settlement for widened roadbed in Shen-Da Expressway reconstruction. Journal of Highway and Transportation Research and Development, 22(11), 18-20. https://doi.org/10.3969/j.issn.1002-0268.2005.11.005 (in Chinese) 
Shi, X. N., Huang, J. J., \& Su, Q. (2020). Experimental and numerical analyses of lightweight foamed concrete as filler for widening embankment. Construction and Building Materials, 250, 118897. https://doi.org/10.1016/j.conbuildmat.2020.118897

$\mathrm{Su}, \mathrm{C} .$, \& Xu, Z. Z. (2000). Analysis method and engineering practice of foundation treatment design of connection section of highways. Journal of Engineering Geology, 8(1), 81-85.

https://doi.org/10.3969/j.issn.1004-9665.2000.01.013 (in Chinese)

Van Meurs, A. N. G., Van Den Berg, A., Venmans, A. A. M., Van, M. A., \& Zwanenburg, C. (1999). Embankment widening with the gap-method. In Twelfth European Conference on Soil Mechanics and Geotechnical Engineering (Proceedings) The Netherlands Society of Soil Mechanics and Geotechnical Engineering; Ministry of Transport, Public Works and Water Management; AP van den Berg Machinefabriek; Fugro NV; GeoDelft; Holland Railconsult (No. Volume 2).

Vos, E., Couvreur, J. F., \& Vermaut, M. (1994). Comparison of numerical analysis with field data of a road widening project on peaty soil. In Advances in Understanding and Modelling the Mechanical Behaviour of Peat: Proceedings of the International Workshop, (pp.16-18) June 1993, Delft, Netherlands.

Wang, H., \& Huang, X. M. (2011). Stress and deformation due to embankment widening with different treatment techniques. Journal of Central South University of Technology, 18(004), 1304-1310. https://doi.org/10.1007/s11771-011-0837-9

Xu, Z. Z., Su, C., He, L. D., Chen, X. T., Guo, Y. C., \& He, P. (1998). Foundation treatment design of the joint section of Xicheng-Huning Expressway. Advances in Science and Technology of Water Resources, 18(2), 49-51. (in Chinese)

Yang, T., Li, L., Shi, L., \& Li, G. W. (2011). Numerical analysis of reinforcement mechanism of separating wall for expressway widening on soft ground. Journal of Highway and Transportation Research and Development, 28(8), 52-56. https://doi.org/10.3969/j.issn.1002-0268.2011.08.010 (in Chinese)

Yu, H., Wang, Y. M., Zou, C., Wang, P., \& Yan, C. (2017). Study on subgrade settlement characteristics after widening project of highway built on weak foundation. Arabian Journal for Science and Engineering, 42(9), 3723-3732. https://doi.org/10.1007/s13369-017-2469-3

Yuan, S. Q., \& Zheng, X. G. (2017). Theory and practice of expressway reconstruction and extension design. China Planning Press, Beijing, China. (in Chinese)

Zhang, J. H. (2011). Analysis of deformation behavior of expressway widening engineering under different foundation treatments. Rock and Soil Mechanics, 32(4), 1216-1222. https://doi.org/10.3969/j.issn.1000-7598.2011.04.044 (in Chinese)

Zhang, J. H., Zheng, J. L., \& Huang, X. M. (2011). Centrifuge model test and numerical analysis of geosynthetic-reinforced embankments for a road widening. In Road Pavement and Material Characterization, Modeling, and Maintenance (pp. 204-210).

\section{Xin Jiang, \\ Yongguo Fu, \\ Linyu Li, \\ Hanyan Gu, \\ Yanjun Qiu}

Design Optimisation Analysis of Isolating Wall for Separated

Widening

Embankment on Soft

Ground 
THE BALTIC JOURNAL OF ROAD AND BRIDGE ENGINEERING

$2021 / 16(2)$

Zhao, M., Liu, C., El-Korchi, T., Song, H., \& Tao, M. (2019). Performance of geogrid-reinforced and PTC pile-supported embankment in a highway widening project over soft soils. Journal of Geotechnical and Geoenvironmental Engineering, 145(11), 06019014.

https://doi.org/10.1061/(ASCE)GT.1943-5606.0002157 